optic neuritis was present. By the perimeter he was found to have well-marked bitemporal hemianopia, the nasal half of the field of vision being perfect. He did not suffer from headaches, but if he stooped he felt as though his head was swelling and would burst. The ribs were quite twice the thickness of normal ones, and markedly thickened at the sternal ends. The sternum was enlarged to a considerable degree, and projects forward. The heart was normal. The spleen and liver were not examined. There was no apparent enlargement of the thyroid. He perspired very freely, and suffered much from thirst. He constantly felt drowsy. Memory for recent events was very bad, but he remembered things that happened years ago well. His gait was slow, measured, with a pronounced stoop, and he had difficulty in getting up and down stairs. Both knees and shoulders were affected with rheumatoid arthritis. In the nineteen days he was under my observation he lost 4 lbs.

REMARKS.

Since August 24th, 1897, the patient has been taking tabloids of "pituitary gland substance," gr. ii (B. W. and Co)., three times a day, with the following result, which I give in his own words, his letter to me being dated November 8th : "I certainly feel much more active than I did, and have lost 8 lbs. since my return from Eastbourne."

\section{VOLVULUS OF MECKEL'S DIVERTICULUM.}

By THOS. CARWARDINE, M.S., F.R.C.S., Assistant Surgeon, Bristol Royal Infirmary.

L. P., aged 2 days, was brought to the Bristol Royal Infirmary on October 15 th, 1897 , on account of intestinal obstruction. The child had been repeatedly sick, bringing up a greenish-brown vomit, and had passed nothing per anum, nor discharge from umbilicus. The belly was much distended, and exploration of the rectum with the finger revealed no cause. The child was watched and treated for six hours, but nothing passed.

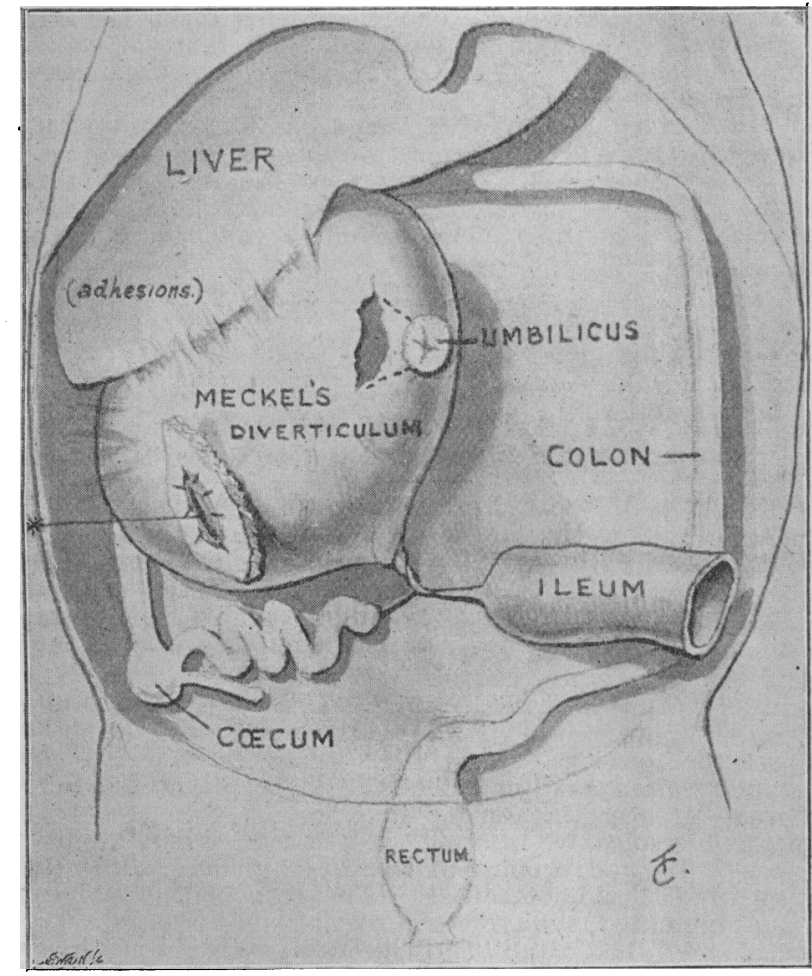

* Enterostomy aperture, with skin attached.

Operation.-The distension appeared more on the left side, and accordingly coliotomy was performed in the left semilunar line. Here the small intestine prosented, very much distended, with lymph upon its surface from peritonitis. The colon, when brought to the surface, was very small, not larger than a crow quill, whitish, empty, and non-sacculated. With the finger in the abdomen I could feel bimanually a mass to the right of the umbilicus. A second incision was therefore made in the right semilunar line, when much distended gut presented, which it was impossible to bring out of the opening, owing to numerous adbesions; and for the same reason the source of obstruction could not be felt, although it seemed almost certain that it was due to an anomaly of Meckel's diverticulum. On making an artificial anus, a considerable quantity, several ounces, of meconium escaped. The cæcum and ascending colon were small, white, and empty. The symptoms persisted, and the child died twentyfour hours later. At the post-mortem examination it was found that a meconium-containing cyst had been opened, produced by a volvulus of Meckel's diverticulnm of some three tarns, as in the figure. Only a fine impervious cord connected it with the bowel below it, and a minute stalk, which would partially admit a bristle, attached it to the distended bowel above, the junction being a $\perp$-shaped one. are :

The points of interest to which attention should be drawn

I. The ante-partum commencement of peritonitis, as shown by the lymph and adhesions of firm character to parts around.

2. The occurrence of the volvulus of Meckel's diverticulum in utero, during late fotal life, so that a meconium-containing cyst was segmented off from the meconium-containing ileum, and therefore obstruction was not relieved by opening the distended diverticulum.

3. The lower 12 inches of small intestine were empty and tortuous, and the colon small and non-sacculated. No meconium had ever passed into them, yet the cæcum and appendix were well formed. This disposes of a common view as to the development of the cæcum.

\section{TRAUMATIC ANEURYSM OF THE ULNAR ARTERY IN THE PALM CURED BY TYING THE ULNAR ARTERY ABOVE THE WRIST.}

By WM. ROBERTSON, M.D.GLas., D.P.H., Assistant Visiting Surgeon and District Physician to the Perth County and City Royal Infirmary.

In the British Medical Journal of September inth Dr. Griffiths has an interesting notice of a case of spontaneous aneurysm of the ulnar artery; and, as he prefaces his report with the remark that aneurysms of small arteries are rare, I am glad to be able to chronicle a somewhat similar case. In this instance there was a distinct cause for the disease; in other words, the aneurysm was traumatic. Briefly, this is the history of the case.

W. G., aged 18, fireman on a railway engine, when seen at the infirmary on August 25 th, complained of a painful spot just under the hypothenar eminence of the left hand. On comparing the two hands one could plainly detect a bulging at the affected part. And with this bulging a pulsation was very noticeable. He had more than once remarked on the " beating." It was, however, the pain that worried him. The swelling was nearly an inch in diameter, and almost circular. When its centre was firmly palpated the pain was increased. Only occasionally had he felt any numbness of the little finger and its neighbour. The patient was a healthy, strapping fellow, muscular and well developed. His heart was normal, and he had never suffered from cough. There was no syphilitic history ; indeed, he had never had a day's illness.

The pulsation in the aneurysm entirely ceased when the ulnar artery was firmly compressed above the wrist. The interesting part of the case lies in the fact that the traumatic cause is distinct. About five months ago W. G. found the injector of his engine very stiff. He gave it a firm knock with his left hand. This caused a sharp pain in the hypothenar eminence. The tenderness was only aggravated by the persistent knocking required to force the handle of the injector. The swelling and pulsation in the hand were noticed for the first time two months ago. This led him to consult a doctor, who recommended painting with iodine. 